\title{
Assessing the Health Education and Literacy Needs of Partner Communities
}

\author{
Mauro Allan P. Amparado * \\ mapamparado@gmail.com
}

Rose Delia P. Ocariza ** rdocariza@yahoo.com

University of Cebu Lapu-Lapu and Mandaue, Mandaue City, Cebu, Philippines

* Director, Community Awareness, Relations \&

Extension Services, UCLM

${ }^{* *}$ Clinical Instructor, College of Nursing, UCLM 


\section{Abstract}

The study assessed the health education and literacy needs of residents in two partner communities of a university. The findings served as basis for the creation of the annual community extension plan of the department.

This study utilized the descriptive quantitative design. It was conducted in 2 partner communities namely Village Looc and Village Opao, both located in Mandaue City, Cebu, Philippines. The survey utilized 90 respondents.

A researcher-made instrument was used which listed 20 concepts. Respondents were requested to determine to what extent they need the discussion of the concepts. To interpret the data, simple percentage and weighted mean was used.

The study reveals that the residents' top ten needs are as follows: Prostate Cancer (2.35); Breast cancer (2.28); Smokingrelated diseases (2.28); Stress (2.27); Diabetes Mellitus (2.25); Asthma (2.25); Dengue (2.20); Tuberculosis (2.15); HIV/AIDS (2.14); Skin diseases (2.13); and Oral Hygiene (2.13). In this study, hypertension was considered the health topic with the lowest need (1.51).

The researchers concluded that there was a moderate need among residents on health education and literacy. The researchers recommended the incorporation of the top ten topics in the annual plan of the college to increase the knowledge of community residents on these health topics.

Keywords: Health Education; Literacy Needs; Prostate Cancer; Breast Cancer; Smoking-related diseases; Mandaue City, Cebu, Philippines. 
Recommended citation: Amparado, M. A. P. \& Ocariza, R. D. P. (2018). Assessing the Health Education and Literacy Needs of Partner Communities. Cebu Journal of Nursing, 1(1), 25-40.

\section{Introduction}

The well-known adage, "If you give a man a fish, you feed him for a day, but if you teach a man how to fish, you feed him for a lifetime," illustrates the importance of client education. The teaching-learning process empowers clients and usually enables them to achieve a higher level of wellness or to manage specific health care needs. Nurses frequently become primary teachers for clients and coordinate and reinforce information from other health care professionals (Craven \& Hirnle, 2003).

Client education is an integral part of nursing care. It is the nurse's responsibility to assist the client to identify the learning needs and resources that will restore and maintain an optimal level of functioning. Client education is extremely important today in a health care environment that demands cost-effective measures. Client education, a hallmark of quality nursing care, is a fiscally responsible intervention that encourages health care consumers to engage in self-care and to develop healthy lifestyle practices (Delaune \& Ladner, 2002).

Health literacy as a discrete form of literacy is becoming increasingly important for social, economic and health development. The positive and multiplier effects of education and general literacy on population health, particularly women's health, are well known and researched. However, a closer analysis of the current HIV/AIDS epidemics, especially in Africa, indicates a complex interface between general literacy and health literacy. While general literacy is an important determinant of health, it is not sufficient to address the major health challenges facing developing 
and developed societies. As a contribution to the health literacy forum in Health Promotion International, this paper reviews concepts and definitions of literacy and health literacy, and raises conceptual, measurement and strategic challenges. It proposes to develop a set of indicators to quantify health literacy using the experience gained in national literacy surveys around the world. A health literacy index could become an important composite measure of the outcome of health promotion and prevention activities, could document the health competence and capabilities of the population of a given country, community or group and relate it to a set of health, social and economic outcomes (Kickbusch, 2001).

The University of Cebu Lapu-Lapu and Mandaue (UCLM) pursues excellence in instruction, research, and community service towards social and economic development as well as environmental sustainability (Amparado, Gimena, Patindol \& Tan, 2013). To determine the needs of a partner community, UCLM has funded a study on community needs assessment. The study was conducted in Village Looc, Mandaue City, Cebu, Philippines. The study revealed that the people of these communities need livelihood, solid waste management, and literacy programs (Amparado, Camayra, Dorio \& Patindol, 2017). The results of the previous study motivated the researchers of this present study to assess the health education and literacy needs of these village. The findings of the study will constitute the various topics which will be taught by clinical instructors and students in the Health Education and Literacy Program (HELP) of the university.

\section{Theoretical Framework}

This study is anchored on Nola J. Pender's Health Promotion Model. The assumptions of the model reflect the behavioral science perspective and emphasize the active role of the patient for managing health behaviors by modifying the environmental 
context. According to Tomey and Alligood (2002), the major assumptions of the model includes:

1. Persons seek to create conditions of living through which they can express their unique human health potential.

2. Persons have the capacity for reflective self-awareness, including assessment of their own competencies.

3. Persons value growth in directions viewed as positive and attempt to achieve a personally acceptable balance between change and stability.

4. Individuals seek to actively regulate their own behavior.

5. Individuals in all their biopsychosocial complexity interact with the environment, progressively transforming the environment and being transformed over time.

6. Health professionals constitute a part of the interpersonal environment, which exerts influence on persons throughout their lifespan.

7. Self-initiated reconfiguration of person-environment interactive patterns is essential to behavior change.

\section{Related Studies}

Health literacy is a relatively new concept in health promotion. It is a composite term to describe a range of outcomes to health education and communication activities. From this perspective, health education is directed towards improving health literacy. In one paper, it identified the failings of past educational programs to address social and economic determinants of health, and traces the subsequent reduction in the role of health education in contemporary health promotion. These perceived failings may have led to significant underestimation of the potential role of health education in addressing the social determinants of health. A 'health outcome model' is presented. This model highlights health literacy as a key outcome from health education. Examination of the concept of health literacy identifies distinctions between functional 
health literacy, interactive health literacy and critical health literacy. Through this analysis, improving health literacy meant more than transmitting information, and developing skills to be able to read pamphlets and successfully make appointments. By improving people's access to health information and their capacity to use it effectively, it is argued that improved health literacy is critical to empowerment. The implications for the content and method of contemporary health education and communication are then considered. Emphasis is given to more personal forms of communication, and community-based educational outreach, as well as the political content of health education, focused on better equipping people to overcome structural barriers to health (Nutbeam, 2000).

Numerous school health education programs have been developed. No matter how effective a given program may be, however, its impact will be determined by the extent to which it is actually disseminated and maintained in classrooms. The dissemination of a program involves purposeful efforts by agencies usually outside the school to implement the program in many different schools, while program implementation involves efforts by those within a given school to effectively use the program in its classrooms. This paper has been prepared to review concepts, strategies, and methods used to study dissemination and implementation; to specify the functions of dissemination and implementation research; and to describe general approaches and specific procedures to evaluate the effectiveness of dissemination and implementation activities. As we develop more and better school health education interventions, the need for research that will allow us to efficiently transport these interventions to classrooms throughout the nation becomes increasingly important (Basch, 1984).

To determine whether community health education can reduce the risk of cardiovascular disease, a field experiment was 
conducted in three northern California towns. In two of these communities there were extensive mass-media campaigns over a 2-year period, and in one of these, face-to-face counselling was also provided for a small subset of high-risk people. The third community served as a control. People from each community were interviewed and examined before the campaigns began and one and two years afterwards to assess knowledge and behavior related to cardiovascular disease (e.g., diet and smoking) and also to measure physiological indicators of risk (e.g., blood pressure, relative weight, and plasma-cholesterol). In the control community the risk of cardiovascular disease increased over the two years but in the treatment communities there was a substantial and sustained decrease in risk. In the community in which there was some faceto-face counselling the initial improvement was greater and health education was more successful in reducing cigarette smoking, but at the end of the second year the decrease in risk was similar in both treatment communities. These results strongly suggest that mass-media educational campaigns directed at entire communities may be very effective in reducing the risk of cardiovascular disease (Farquhar, Wood, Breitrose, Haskell, Meyer, Maccoby \& Stern, 1977).

In another study, it tracked 1741 older alumni of the University of Pennsylvania found that, indeed, a healthy lifestyle reduced not only their risk of dying but also their disability in later years. The study subjects, who have attended the University in 1939 and 1940, were surveyed on their smoking habits, body-mass index (BMI), and exercise patterns and, beginning in 1986, chronic conditions, use of medical services, and extent of disability. The alumni were classified into three risk groups, the highest risk belonging to obese, inactive smokers. Those in the highest risk group had twice the cumulative disability of those with low risks, and the onset of disability was postponed by almost eight years in the low risk group. This evidence indicates that, as in younger age groups, the behaviors that most significantly affect health in older 
people are smoking, obesity, and physical inactivity. However, the recently observed compression of morbidity cannot entirely be explained by improvements in these factors. The reduced prevalence of smoking over the past several decades is no doubt responsible in part for the fact that the elderly are healthier than they used to be. But the increased prevalence of overweight, obesity, and physical inactivity would be expected to have the opposite effect, leading to increased disability in older people (Schneider, 2011).

\section{Objectives}

The study assessed the health education and literacy needs of residents in two partner communities of a university. The findings served as basis for the creation of the annual community extension plan of the department.

\section{Methods}

This study utilized the descriptive quantitative design. It was conducted in 2 partner communities namely Village Looc and Village Opao, both located in Mandaue City, Cebu, Philippines. The survey utilized 90 respondents.

A researcher-made instrument was used which listed 20 concepts. Respondents were requested to determine to what extent they need the discussion of the concepts.

To interpret the data, simple percentage and weighted mean was used. For the interpretation, the following ranges were utilized:

$\begin{array}{lll}2.32-3.00 & - & \text { High Need } \\ 1.66-2.31 & - & \text { Moderate Need } \\ 1.00-1.65 & - & \text { Low Need }\end{array}$




\section{Results and Discussion}

The table below shows the needs assessment of health education and literacy concepts in two villages. The study shows that the residents' top five needs are as follows: Prostate Cancer (2.35); Breast cancer (2.28); Smoking-related diseases (2.28); Stress (2.27); Diabetes Mellitus (2.25).

Prostate Cancer is a malignancy of the prostate gland. After the age of 60 , approximately one-third of males experience an enlargement of the prostate gland. This is known as benign prostatic hyperplasia (BPH). This enlargement compresses the prostatic urethra, resulting in difficulty in urination. These males experience frequent urinations with small amounts of urine, a decrease in the strength of the urinary stream, occasional bedwetting, and a sense of incomplete voiding. Approximately $15 \%$ of men with $\mathrm{BPH}$ require medical treatment. Prostatic cancer is the third leading cause of cancerous death in males 55 years of age or older. Prostatic cancer also causes enlargement of the prostate gland, producing difficulty in urination (Rizzo, 2010).

In the study of Jalang and Amparado (2017) on Compliance with Discharge Instructions among Prostatectomy Patients, findings revealed that the subjects were in their late adulthood, with monthly income below 5,000 Philippine pesos, elementary graduates, and their spouse as the primary caregiver. The subjects were moderately compliant on medications, physical exercise, treatment/procedures and diet. They were highly compliant on health teachings, and reporting observable signs and symptoms but were not compliant on bladder exercise.

Breast Cancer, on the other hand, is the most commonly occurring cancer in women (one out of eight) in the United States according to the National Cancer Institute; all women should be 
considered at risk for developing breast cancer because $80 \%$ of women with breast cancer fail to exhibit the specific risk factors associated with cancer. Long-term survival rates for breast cancer have a direct correlation to early detection of the disease. Nurses play a major role in women's health by teaching breast selfexamination and by supporting women in achieving healthier lifestyles believed to decrease the risk factors of Breast Cancer (Firth \& Watanabe, 1996 as cited by Delaune \& Ladner, 2002; Estes, 2002 as cited by Delaune \& Ladner, 2002).

Cigarette smoking is associated with a number of diseases, including heart disease, chronic obstructive lung disease, and lung cancer. Cigarette smoking can worsen peripheral vascular and coronary artery diseases. Inhaled nicotine causes vasoconstriction of peripheral and coronary blood vessels, increasing blood pressure, and decreasing blood flow to peripheral vessels. The risk of lung cancer is ten times greater for a person who smokes than for a nonsmoker. Exposure to secondhand smoke increases the risk of lung cancer and cardiovascular disease in the nonsmoker (JNC 1997 as cited by Potter \& Perry, 2004; AHA, 2001 as cited by Potter \& Perry, 2004).

The fourth need was on the concept of stress. A universal experience, stress can be a catalyst for positive change, or it can be the source of discomfort and pain. Stress can be contagious. Caring for clients who are experiencing high levels of anxiety can be stress-provoking for nurses. Nurses are involved with stress management from a teaching perspective, helping clients learn to cope with the stress imposed by illness, injury, disability, or treatment approaches. Nurses also encounter stress as a personal experience. Successful stress management is necessary for wellness of both clients and nurses (Daniels, Wilkins \& Grendell, 2010). 
On the $5^{\text {th }}$ spot is Diabetes Mellitus. Diabetes is an independent risk factor for Myocardial Infarction and stroke. People with diabetes often have other risk factors, such as high cholesterol and obesity, that further increase the risk. The risk of disease is three times greater in diabetic women and twice as great in diabetic men (Craven \& Hirnle, 2003).

Diet, insulin, exercise, blood glucose monitoring, and treatment of co-morbidities are essential elements for diabetes management. However, two studies show that subjects are noncompliant on exercise and blood glucose monitoring (Marikit \& Amparado, 2017; Genabe \& Amparado, 2015).

Still on the top ten list, the residents also would like the College of Nursing to teach them on Asthma (2.25); Dengue (2.20); Tuberculosis (2.15); HIV/AIDS (2.14); Skin diseases (2.13); and Oral Hygiene (2.13). In this study, hypertension was considered the health topic with the lowest need (1.51).

Asthma is an inflammatory disease which is caused by the narrowing of airways. This disease results to difficulty in breathing, coughing, wheezing, and shortness of breath. Asthma may be triggered by pollutants, airborne substances, and irritants. On the other hand, Tuberculosis, also a lung-related disease, is caused by a bacteria called Mycobacterium Tuberculosis and considered to be contagious and can kill people if left untreated. This disease is very common in the Western Pacific, Africa, and Southeast Asia.

Dengue is a serious public health concern in the Philippines. The disease is caused by a mosquito-borne virus. The Philippines has the highest cases and deaths in Southeast Asia. The implementation of 4-S, as advocated by the Department of Health, is highly encouraged. This includes search \& destroy, selfprotection measures, seeking early consultation, and support 
fogging/spraying in hotspot areas. In the study of Rufo and Amparado (2017), community residents have moderate implementation of search \& destroy, and self-protection measures. In addition, Acosta and Amparado (2017) presented in their study that the respondents in Tagbilaran City, Bohol have poor implementation measures on the use of mosquito repellants, mosquito nets at daytime, and the use of household insecticide aerosol, insecticide vaporizers, or mosquito coils. Most of them recognized the early signs and symptoms of dengue such as severe headache and fever. Nearly all mothers brought their child to the nearest health facility as part of their initial management every time their child experiences fever. Most of them do not agree on the use of fogging measures to be done against dengue control.

HIV/AIDS is a disease caused by a virus which attacks the immune system of person. As a public health concern, HIV/AIDS is surrounded by stigma. People are afraid to be tested and those who have the disease are afraid to avail of treatment due to discrimination. In the study of Famador \& Amparado (2018), the informants mentioned that they will not dine with persons living with HIV. They also believe that persons living with HIV have shorter life span. Discrimination was also discussed in the study of Ortega, Bicaldo, Sobritchea \& Tan (2005), revealing that discrimination associated with this disease has been found to be a hindrance to the development of successful preventive measures, as it discourages people living with HIV/AIDS and other people from contacting health and social services.

Skin diseases are common in poor communities. This is brought about by poor living conditions, nutrition, and ventilation. Oral hygiene is also poor in these areas inasmuch as hygiene is not a priority. Poor families would rather buy food than allocate their money to hygiene products. 
Health centers and stations in these communities should be equipped with facilities, personnel, medicines and supplies. Montecillo \& Amparado (2015) revealed in their study that most health centers lack medicines and supplies.

It is important to teach these individuals with health concepts to increase awareness and to address health conditions immediately. Client education promotes wellness, prevents illness, restores optimal health and function if illness has occurred. It also assists clients and families to cope with alterations in health status. However, health education and literacy will be most effective if resources are also available to address health concerns.

\section{Needs Assessment of Health Education \& Literacy Concepts}

\begin{tabular}{|l|c|c|c|}
\hline $\begin{array}{l}\text { Health Education } \\
\text { Concepts }\end{array}$ & Mean & Interpretation & Rank \\
\hline Prostate Cancer & 2.35 & High need & 1 \\
\hline Breast Cancer & 2.28 & Moderate need & 2 \\
\hline Smoking-related diseases & 2.28 & Moderate need & 3 \\
\hline Stress & 2.27 & Moderate need & 4 \\
\hline Diabetes Mellitus & 2.25 & Moderate need & 5.5 \\
\hline Asthma & 2.25 & Moderate need & 5.5 \\
\hline Dengue Fever & 2.20 & Moderate need & 7 \\
\hline Tuberculosis & 2.15 & Moderate need & 8 \\
\hline HIV/AIDS & 2.14 & Moderate need & 9 \\
\hline Skin diseases & 2.13 & Moderate need & 10.5 \\
\hline Oral hygiene & 2.13 & Moderate need & 10.5 \\
\hline Conjunctivitis & 2.11 & Moderate need & 12 \\
\hline Pneumonia & 2.06 & Moderate need & 13 \\
\hline Family Planning & 2.00 & Moderate need & 14 \\
\hline Helminthiasis & 1.95 & Moderate need & 15 \\
\hline Malnutrition & 1.90 & Moderate need & 16 \\
\hline Dementia & 1.87 & Moderate need & 17 \\
\hline
\end{tabular}




\begin{tabular}{|l|c|c|c|}
\hline Osteoporosis & 1.84 & Moderate need & 18 \\
\hline Fractures & 1.66 & Moderate need & 19 \\
\hline Hypertension & 1.51 & Low need & 20 \\
\hline Grand Mean & 2.06 & Moderate Need & \\
\hline
\end{tabular}

\section{Conclusion}

This descriptive study assessed the health education and literacy needs of residents in two villages of Mandaue City, Cebu, Philippines. The researchers concluded that there was a moderate need among residents on health education and literacy. The researchers recommended the incorporation of the top ten topics in the annual plan of the college to increase the knowledge of community residents on these health topics.

\section{Literature Cited}

Acosta, E. E., \& Amparado, M. A. P. (2020). Dengue Control Measures in Tagbilaran City, Bohol, Philippines. Journal of Research in Nursing, 3(1), 20-29.

Amparado, M. A. P., Camayra, M. T., Dorio Jr., P. A., \&

Patindol, D. B. (2017). Sustainable Community Extension Programs for Village Looc, Mandaue City, Cebu, Philippines: The 8th Year Re-assessment. IAMURE, 19(1), 102-114.

Amparado, M. A. P., Gimena, J. A. F., Patindol, D. B. \& Tan, R. D. (2013). University of Cebu Research Center Manual. Philippines: University of Cebu.

Basch, C. E. (1984). Research on disseminating and implementing health education programs in schools. Health education, 15 (4), 57-66. 
Craven, R. F. \& Hirnle, C. J. (2003). Fundamentals of Nursing: Human Health and Function. $4^{\text {th }}$ edition. Hong Kong: Lippincott Williams \& Wilkins.

Daniels, R., Wilkins, R. N. \& Grendell, F. R. (2010). Fundamentals of Nursing: Nursing Human Functions. Singapore: Delmar.

Delaune, S. C. and Ladner, P. K. (2002). Fundamentals of Nursing: Standards and Practice. $2^{\text {nd }}$ edition. Singapore: Delmar.

Famador, M. C. \& Amparado, M. A. P. (2018). Targeting Wellness, Examining the Scourge: Views from the Academe on HIV/AIDS. Paper presented in the 2018 University of Cebu Research Congress, University of Cebu, Cebu City, Cebu, Philippines, 12(1), 21.

Farquhar, J., Wood, P., Breitrose, H., Haskell, W., Meyer, A., Maccoby, N. \& Stern, M. (1977). Community education for cardiovascular health. The Lancet, 309 (8023), 1192-1195.

Genabe, H. F. M. \& Amparado, M. A. P. (2015). Exercise and Blood Glucose Monitoring Compliance among Diabetics. Journal of Research in Nursing, 1(1), 40-49.

Jalang, J. D. R. \& Amparado, M. A. P. (2017). Compliance with Discharge Instructions among Prostatectomy Patients. IAMURE International Journal of Social Sciences, 19 (1), 3957.

Kishbusch, I. S. (2001). Health literacy: addressing the health and education divide. Health promotion international, 16(3), 289297. 
Marikit, M. E. \& Amparado, M. A. P. (2017). Socio-cultural

Dimensions in Treatment and Compliance of Type 2 Diabetics. Journal of Research in Nursing, 3(1), 40-49.

Montecillo, C. P. V. \& Amparado, M. A. P. (2015).

Community Health Needs of Barangay Hipodromo, Cebu City, Cebu, Philippines. Journal of Research in Nursing, 1(1), 2029.

Nutbeam, D. (2000). Health literacy as a public health goal: a challenge for contemporary health education and communication strategies into the $21^{\text {st }}$ century. Health promotion international, 15 (3), 259-267.

Ortega, N. L., Bicaldo, B. F., Sobritchea, C. \& Tan M. L. (2005). Exploring the realities of HIV/AIDS-related discrimination in Manila, Philippines. AIDS care, 17(sup2), 153-164.

Potter, P. A. \& Perry, A. G. (2004). Fundamentals of Nursing. $6^{\text {th }}$ edition. Singapore: Elsevier (Singapore) Pte. Ltd.

Rizzo, D. C. (2010). Fundamental of Anatomy and Physiology. $3^{\text {rd }}$ edition. New York: Delmar, Cengage Learning.

Rufo, F. J. M., \& Amparado, M. A. P. (2017). Implementation of Dengue Control Measures in City of Naga, Cebu, Philippines. IAMURE, 58.

Schneider, M. J. (2011). Introduction to Public Health. $3^{\text {rd }}$ edition. Singapore: Jones and Bartlett Publishers.

Tomey, A. M. and Alligood, M. R. (2002). Nursing Theorists and Their Work. $5^{\text {th }}$ edition. Singapore: Mosby Inc. 